\title{
THE SYNTHESIS OF SALICYLATE PROMPTED BY BRØNSTED ACIDIC IONIC LIQUIDS
}

\author{
DONG JIANG, JIE LIU, YUAN YUAN WANG, LI YI DAI* \\ Shanghai Key Laboratory of Green Chemistry and Chemical Processes, Department of Chemistry, East China Normal University, \\ Shanghai 200062, P. R. China \\ (Received 7 March 2008 - Accepted 24 October 2008)
}

\begin{abstract}
Brønsted acidic ionic liquids based on imidazolium cation were employed as a series of efficient and environmentally benign catalysts and solvents for the synthesis of salicylate, the yields could reach $76 \%-96 \%$. The optimal reaction conditions were determined. The results showed that Brønsted acidic ionic liquids were efficient catalysts and solvents which could be recycled easily without obvious decline in catalytic activities.
\end{abstract}

Key words: Ionic liquid, esterification, salicylate

\section{INTRODUCTION}

Salicylate was a kind of very useful organic compound, which could be used as essence, medicine, solvent and so on. The traditional catalysts used for the synthesis of salicylate were concentrated sulfuric acid and phosphoric acid which were strongly corrosive, harmful to environment and unreusable. When using concentrated sulfuric acid and phosphoric acid as catalysts, it also brought difficulty to the final treatment of the synthesis of salicylate ${ }^{1}$. Toluene-p-sulfonic acid, sodium acid sulfate and solid acid had been used as substitute catalysts for the synthesis of salicylate, but the recovery of them was difficult ${ }^{1-3}$.

Brønsted acidic ionic liquids (ILs) 1-butyl-3-methyl-imidazolium hydrogen sulphate ([bmim] $\left.\mathrm{HSO}_{4}\right)$, 1-butyl-3-methyl-imidazolium dihydogen phosphate ([bmim $\left.] \mathrm{H}_{2} \mathrm{PO}_{4}\right)$, 1-methyl-3-hydro-imidazolium tetrafluoroborate ([Hmim] $\left.\mathrm{BF}_{4}\right)$, 1-methyl-3-(3-sulfopropyl)-imidazolium hydrogen sulphate ([ $\mathrm{HSO}_{3}$ pmim] $\mathrm{HSO}_{4}$ ), 1-methyl-3-(3-sulfopropyl)-imidazolium tetrafluoroborate $\left(\left[\mathrm{HSO}_{3}\right.\right.$-pmim] $\left.\mathrm{BF}_{4}\right)$ and 1-methyl-3-(3-sulfopropyl)-imidazolium

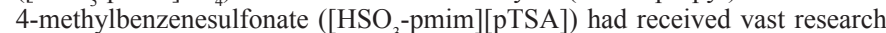
interests in recent years which had been used as satisfactory acidic catalysts and solvents for many organic reactions ${ }^{4-6}$, due to their particular properties, such as high thermal stability, reusability, miscibility with organic compounds and so on ${ }^{7-9}$. In this paper, an efficient and feasible procedure for the synthesis of salicylate was reported, using Brønsted acidic ILs [bmim] $\mathrm{HSO}_{4}$, [bmim] $\mathrm{H}_{2} \mathrm{PO}_{4},[\mathrm{Hmim}] \mathrm{BF}_{4},\left[\mathrm{HSO}_{3}-\mathrm{pmim}\right] \mathrm{HSO}_{4},\left[\mathrm{HSO}_{3}-\mathrm{pmim}_{\mathrm{BF}_{4}}\right.$ and $\left[\mathrm{HSO}_{3}-\mathrm{pmim}\right]$ [pTSA] (Figure 1) as recyclable catalysts and solvents (Scheme 1). The optimal reaction conditions were determined and the results showed that Brønsted acidic ILs were efficient catalysts and solvents for the synthesis of salicylate. ILs used could be recycled easily without obvious decline in catalytic activities.

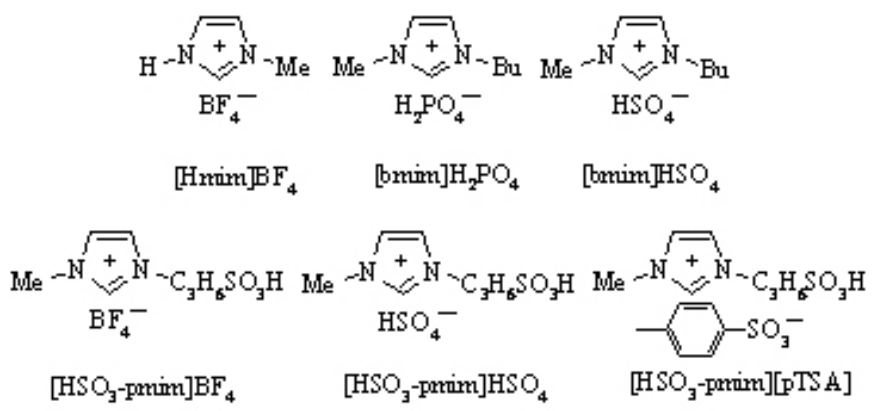

Figure $1 \mathbb{L}$ s synthesized for the synthesis of salicylate

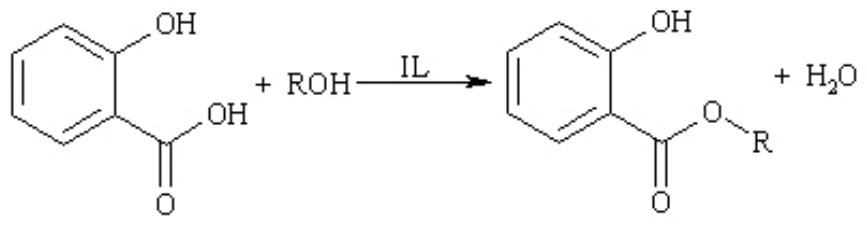

Sc heme 1 The synthesis of salicylate

\section{EXPERIMENTAL}

$\mathrm{N}$-methylimidazole and 1-butylbromide were purchased and distilled before using. All the other reagents used were purchased and used without any further purification.

The synthesized salicylates were characterized by FT-IR (Nicolet Nexus 670 ) and GC (Agilent 6890-5973N). The results of GC showed that the purities of salicylates were higher than $99 \%{ }^{10-14}$.

Preparation of ILs: ILs used were synthesized according to the previously published papers ${ }^{4-6,15}$.

Typical esterification procedure: Alcohol $(20 \mathrm{mmol})$, salicylic acid $(20$ $\mathrm{mmol})$ and IL $(20 \mathrm{mmol})$ were added into a flask and stirred at $115^{\circ} \mathrm{C}$ for $10 \mathrm{~h}$. Upon completion of the reaction, the reaction mixture became biphasic. The upper phase was salicylate and the lower phase was IL. The upper phase was separated, washed with water and saturated solution of sodium hydrogen carbonate, and dried over anhydrous sodium sulfate. Then salicylate was characterized by FT-IR and GC. The lower phase was rotatory evaporated and IL was reused after removal of water under vacuum $\left(0.01\right.$ Torr) at $80^{\circ} \mathrm{C}$ for $6 \mathrm{~h}$.

\section{RESULTS AND DISCUSSION}

\section{The optimization of reaction conditions}

The results of the optimization of reaction conditions were listed in Table 1. The effect of reaction temperature on the yield was shown in entries 1,2 and 3. When the reaction temperature was $100^{\circ} \mathrm{C}$, the yield was only $28 \%$ (entry 1 ). However, when the reaction temperature was higher than $115^{\circ} \mathrm{C}$, the increase in the yield was slightly, $51 \%$ for $115^{\circ} \mathrm{C}$ and $53 \%$ for $130^{\circ} \mathrm{C}$ (entries 2 and 3 ). So the optimal reaction temperature was $115^{\circ} \mathrm{C}$.

The effect of molar ratio on the yield was shown in entries 2, 4 and 5, the optimal molar ratio (acid: alcohol: IL) was 1: 1: 1 . When the molar ratio was higher than 1: 1: 1 , the increase in the yield was also slightly, $51 \%$ for $1: 1: 1$ and $52 \%$ for $1: 1: 1.5$ (entries 2 and 5 ).

As can be seen, the yields of salicylate for $4 \mathrm{~h}$ and $7 \mathrm{~h}$ were not satisfactory, $51 \%$ for $4 \mathrm{~h}$ and $64 \%$ for $7 \mathrm{~h}$ (entries 2 and 6 ). When the reaction time reached $10 \mathrm{~h}$, the yield could reach $86 \%$ (entry 7 ). Then prolonging the reaction time, there was no obvious increase in the yield, $88 \%$ for $12 \mathrm{~h}$ (entry 8 ). So the optimal reaction time was $10 \mathrm{~h}$.

Therefore, the optimal reaction conditions were: molar ratio (acid: alcohol: IL), 1: 1: 1 ; reaction time, $10 \mathrm{~h}$; reaction temperature, $115^{\circ} \mathrm{C}$. 
Table 1 The results of the optimization of reaction conditions

\begin{tabular}{|c|c|c|c|c|c|c|}
\hline Entry & Alcohol & IL & $\begin{array}{l}\text { Reaction } \\
\text { time }(\mathrm{h})\end{array}$ & $\begin{array}{l}\text { Reaction } \\
\text { temperature } \\
\left({ }^{\circ} \mathrm{C}\right)\end{array}$ & $\begin{array}{l}\text { Molar } \\
\text { ratio } \\
\text { (acid: } \\
\text { alcohol: } \\
\quad \text { IL) }\end{array}$ & $\begin{array}{l}\text { Yield } \\
(\%)\end{array}$ \\
\hline 1 & \multirow{8}{*}{$\begin{array}{l}\text { ethyl } \\
\text { alcohol }\end{array}$} & \multirow{8}{*}{$\left.\underset{\mathrm{BF}_{4}}{[\mathrm{Hmim}}\right]$} & 4 & 100 & 1: $1: 1$ & 28 \\
\hline 2 & & & 4 & 115 & 1: $1: 1$ & 51 \\
\hline 3 & & & 4 & 130 & 1: $1: 1$ & 53 \\
\hline 4 & & & 4 & 115 & $1: 1: 0.5$ & 44 \\
\hline 5 & & & 4 & 115 & $1: 1: 1.5$ & 52 \\
\hline 6 & & & 7 & 115 & 1: $1: 1$ & 64 \\
\hline 7 & & & 10 & 115 & $1: 1: 1$ & 86 \\
\hline 8 & & & 12 & 115 & $1: 1: 1$ & 88 \\
\hline
\end{tabular}

\section{The synthesis of salicylate in Brønsted acidic ILs}

The synthesis of salicylate was carried out in Brønsted acidic ILs [bmim] $\mathrm{HSO}_{4},[\mathrm{bmim}] \mathrm{H}_{2} \mathrm{PO}_{4},[\mathrm{Hmim}] \mathrm{BF}_{4},\left[\mathrm{HSO}_{3}\right.$-pmim $] \mathrm{HSO}_{4},\left[\mathrm{HSO}_{3}-\mathrm{pmim}_{3} \mathrm{BF}_{4}\right.$ and $\left[\mathrm{HSO}_{3}\right.$-pmim] [pTSA]. The results were listed in Table 2 showing good yields. The reactants had good solubilities in Brønsted acidic ILs while salicylate was almost immiscible with ILs. Therefore, the esterification started as a homogeneous process and ended as biphasic which could facilitate the separation of salicylate from the reaction mixture and promote the forward reaction of the synthesis of salicylate. Upon completion of the reaction, the upper phase was salicylate and the lower phase was IL, so salicylate could be separated easily. No volatile ILs as catalysts and solvents for the synthesis of salicylate could be reused easily after removal of water under vacuum.

The results of the synthesis of salicylate in Brønsted acidic ILs were shown in Table 2, the catalytic activities of Brønsted acidic ILs were decreased over the following series: $[\mathrm{bmim}] \mathrm{HSO}_{4}>[\mathrm{Hmim}] \mathrm{BF}_{4}>[\mathrm{bmim}] \mathrm{H}_{2} \mathrm{PO}_{4} ;\left[\mathrm{HSO}_{3}\right.$-pmim $]$ $\mathrm{HSO}_{4}>\left[\mathrm{HSO}_{3}-\right.$ pmim $] \mathrm{BF}_{4}>\left[\mathrm{HSO}_{3}-\right.$ pmim $][\mathrm{pTSA}]$. Y. L. Gu had indicated that the acidity sequence of Brønsted acidic ILs [bmim] $\mathrm{HSO}_{4},[\mathrm{Hmim}] \mathrm{BF}_{4}$ and $[\mathrm{bmim}] \mathrm{H}_{2} \mathrm{PO}_{4}$ was $[\mathrm{bmim}] \mathrm{HSO}_{4}>\left[\mathrm{Hmim}_{3}\right] \mathrm{BF}_{4}>[\mathrm{bmim}] \mathrm{H}_{2} \mathrm{PO}_{4}{ }^{16}$. The acidity sequence and the catalytic activity sequence of $[\mathrm{bmim}] \mathrm{HSO}_{4},[\mathrm{Hmim}] \mathrm{BF}_{4}$ and $[\mathrm{bmim}] \mathrm{H}_{2} \mathrm{PO}_{4}$ revealed that the catalytic activities of Brønsted acidic ILs were related to their acidities, the strong acidic IL had higher catalytic activity than the weak acidic IL. From the mechanism of the synthesis of salicylate (Scheme 2), it also could find that when using the strong acidic IL as catalyst and solvent, the synthesis of salicylate from alcohol and salicylic acid was easier. For the catalytic activity sequence of Brønsted acidic ILs containing sulfonic acid groups was $\left[\mathrm{HSO}_{3}-\mathrm{pmim}\right] \mathrm{HSO}_{4}>\left[\mathrm{HSO}_{3}-\mathrm{pmim}^{-} \mathrm{BF}_{4}>\left[\mathrm{HSO}_{3}\right.\right.$ pmim] [pTSA], the acidity sequence of them should be $\left[\mathrm{HSO}_{3}\right.$-pmim] $\mathrm{HSO}_{4}>$ $\left[\mathrm{HSO}_{3}\right.$-pmim $] \mathrm{BF}_{4}>\left[\mathrm{HSO}_{3}\right.$-pmim $][\mathrm{pTSA}]$.

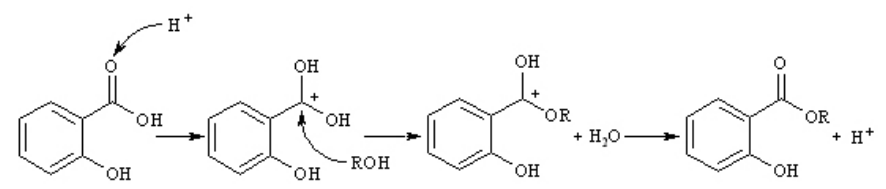

Scheme 2 The mechanism of the synthesis of salicylate

In the synthesis of salicylate using Brønsted acidic ILs as catalysts and solvents, the yields increased from methyl alcohol to n-octyl alcohol orderly $(82 \%, 85 \%, 86 \%, 88 \%$ and $90 \%$, entries $1-5)$. For the boiling points of alcohols increased from methyl alcohol to n-octyl alcohol orderly, the amounts of alcohols in the gas phase decreased from methyl alcohol to n-octyl alcohol during the reaction process. Therefore, the yield of salicylate using the highboiling alcohol was higher than that using the low-boiling alcohol.
Table 2 The results of the synthesis of salicylate in Brønsted acidic ILs

\begin{tabular}{|c|c|c|c|}
\hline Entry & IL & Alcohol & Yield (\%) \\
\hline 1 & \multirow{5}{*}{$\begin{array}{c}{\left[\mathrm{HSO}_{3} \text {-pmim }\right]} \\
\mathrm{HSO}_{4}\end{array}$} & methyl alcohol & 82 \\
\hline 2 & & ethyl alcohol & 85 \\
\hline 3 & & n-butyl alcohol & 86 \\
\hline 4 & & n-hexyl alcohol & 88 \\
\hline 5 & & n-octyl alcohol & 90 \\
\hline 6 & \multirow{5}{*}{$\begin{array}{c}{\left[\mathrm{HSO}_{3} \text {-pmim }\right]} \\
\mathrm{BF}_{4}\end{array}$} & methyl alcohol & 80 \\
\hline 7 & & ethyl alcohol & 83 \\
\hline 8 & & n-butyl alcohol & 85 \\
\hline 9 & & n-hexyl alcohol & 86 \\
\hline 10 & & n-octyl alcohol & 88 \\
\hline 11 & \multirow{5}{*}{$\begin{array}{c}{\left[\mathrm{HSO}_{3} \text {-pmim] }\right.} \\
{[\mathrm{pTSA}]}\end{array}$} & methyl alcohol & 76 \\
\hline 12 & & ethyl alcohol & 78 \\
\hline 13 & & n-butyl alcohol & 81 \\
\hline 14 & & n-hexyl alcohol & 83 \\
\hline 15 & & n-octyl alcohol & 84 \\
\hline 16 & \multirow{5}{*}[\mathrm{bmim}]{$\mathrm{HSO}_{4}$} & methyl alcohol & 86 \\
\hline 17 & & ethyl alcohol & 90 \\
\hline 18 & & n-butyl alcohol & 91 \\
\hline 19 & & n-hexyl alcohol & 93 \\
\hline 20 & & n-octyl alcohol & 96 \\
\hline 21 & \multirow{5}{*}[\mathrm{Hmim}]{$\mathrm{BF}_{4}$} & methyl alcohol & 84 \\
\hline 22 & & ethyl alcohol & 86 \\
\hline 23 & & n-butyl alcohol & 88 \\
\hline 24 & & n-hexyl alcohol & 91 \\
\hline 25 & & n-octyl alcohol & 92 \\
\hline 26 & \multirow{5}{*}[\mathrm{bmim}]{$\mathrm{H}_{2} \mathrm{PO}_{4}$} & methyl alcohol & 7 \\
\hline 27 & & ethyl alcohol & 9 \\
\hline 28 & & n-butyl alcohol & 12 \\
\hline 29 & & n-hexyl alcohol & 15 \\
\hline 30 & & n-octyl alcohol & 16 \\
\hline
\end{tabular}

One important advantage of using Brønsted acidic ILs as efficient catalysts and solvents was the possibility of recycling. We examined the synthesis of n-butyl salicylate in $[\mathrm{Hmim}] \mathrm{BF}_{4}$. The results of recycling experiments were summarized in Table 3. For each cycling reaction, n-butyl alcohol (20mmol), salicylic acid $(20 \mathrm{mmol})$ and recovered $[\mathrm{Hmim}] \mathrm{BF}_{4}$ were added into a flask successively and stirred at $115^{\circ} \mathrm{C}$ for $10 \mathrm{~h}$. Upon completion of the reaction, salicylate was separated and $[\mathrm{Hmim}] \mathrm{BF}_{4}$ was reused after removal of water. The results of recycling use of [ $\mathrm{Hmim}^{4} \mathrm{BF}_{4}$ revealed that Brønsted acidic ILs as catalysts and solvents for the synthesis of salicylate were recyclable. The slightly decline in the yield should be ascribed to the slightly lose of IL. 
Table 3 The results of recycling use of $[\mathrm{Hmim}] \mathrm{BF}_{4}$ in the synthesis of n-butyl salicylate

\begin{tabular}{|c|c|c|c|c|c|}
\hline Entry & 1 & 2 & 3 & 4 & 5 \\
\hline Yield (\%) & 88 & 86 & 85 & 85 & 82 \\
\hline
\end{tabular}

\section{CONCLUSIONS}

In summary, a procedure for the synthesis of salicylate in Brønsted acidic ILs has been developed. The synthesis of salicylate, using Brønsted acidic ILs $[\mathrm{bmim}] \mathrm{HSO}_{4},[\mathrm{bmim}] \mathrm{H}_{2} \mathrm{PO}_{4},[\mathrm{Hmim}] \mathrm{BF}_{4},\left[\mathrm{HSO}_{3}\right.$-pmim $] \mathrm{HSO}_{4},\left[\mathrm{HSO}_{3}\right.$-pmim $]$ $\mathrm{BF}_{4}$ and $\left[\mathrm{HSO}_{3}\right.$-pmim] $[\mathrm{pTSA}]$ as catalysts and solvents, has several advantages: (1) ILs as catalysts show good catalytic activities, the yields could reach $76 \%$ $96 \%$, except [bmim $] \mathrm{H}_{2} \mathrm{PO}_{4}$; (2) For salicylate could not dissolve in ILs, ILs as solvents could promote the forward reaction and facilitate the separation of salicylate from the reaction mixture; (3) ILs could be reused easily after removal of water without obvious decline in catalytic activities.

\section{ACKNOWLEDGEMENTS}

This project was supported by the Key Project of Chinese Ministry of Education (No. 105075).

\section{REFERENCES}

1. D. Y. Yu, T. Q. Ren, T. Z. Ma, Ind. Catal. 14, 42, (2006)

2. M. M. Tang, Q. Y. Lai, K. Liu, M. Liang, Tech. \& Dev. Chem. Ind. 32, 6, (2003)

3. L. B. Peng, A. H. Shi, W. C. Fu, Fine Chem. Intermed. 33, 18, (2003)

4. J. Fraga-Dubreuil, K. Bourahla, M. Rahmouni, J. P. Bazureau, J. Hamelin, Catal. Commun. 3, 185, (2002)

5. H. P. Zhu, F. Yang, J. Tang, M. Y. He, Green Chem. 5, 38, (2003)

6. H. L. Li, S. T. Yu, F. S. Liu, C. X. Xie, L. Li, Catal. Commun. 8, 1759, (2007)

7. J. G. Huddleston, R. D. Rogers, Chem. Commun., 1765, (1998)

8. D. Jiang, Y. Y. Wang, H. Sun, L. Y. Dai, J. Chil. Chem. Soc. 52, 1302, (2007)

9. A. J. Carmichael, D. M. Haddleton, S. A. F. Bon, Chem. Commun., 1237, (2000)

10. F. Toribio, J. Catalan, F. Amat, A. U. Acuna, J. Phys. Chem. 87, 817, (1983)

11. M. M. Radhi, M. F. El-Bermani, Spectrochim. Acta Part A 46, 33, (1990)

12. R. S. Rasmussen, R. R. Brattain, J. Am. Chem. Soc. 71, 1073, (1949)

13. P. R. Jones, C. E. Malmberg, C. McGrattan, J. Pharm. Sci. 64, 1240, (1975)

14. T. Maki, K. Ishihara, H. Yamamoto, Org. Lett. 7, 5047, (2005)

15. H. B. Xing, T. Wang, Z. H. Zhou, Y. Y. Dai., J. Mol. Catal. A: Chem. 264, 53, (2007)

16. Y. L. Gu, J. Zhang, Z. Y. Duan, Y. Q. Deng, Adv. Synth. Catal. 347, 512, (2005) 